\title{
Employee on Boarding Process Automation
}

\author{
Khushboo Nalband*, Priyanka Jadhav**, Geetanjali Salunke*** \\ *Department of Information Technology, AISSMS IOIT, \\ **Department of Information Technology, AISSMS IOIT, \\ ***Department of Information Technology, AISSMS IOIT,
}

\begin{abstract}
On boarding, also known as organizational socialization, plays a vital role in building the initial relationship between an organization and an employee. It also contributes to an employees' satisfaction, better performance and greater organizational commitment thus increasing an employees' effectiveness and productivity in his/her role. Therefore, it is essential that on boarding process of an organization is efficient and effective to improve new employees' retention. Generally this on boarding process is done manually which is time consuming and monotonous. To enhance this process, the proposed solution automates the on boarding or joining process. It will enable HR, ADMINISTRATOR and IT to complete this process by robot which will automatically perform the actions taken to complete the on boarding process. To complete this process direct access is given to applications, where as in automation, robot will perform all the actions taken to complete the process, which is a secured way to access applications. This will thus improve the timeframe and efficiency to complete the on boarding or joining process.
\end{abstract}

Keywords: efficiency, on boarding, productivity, retention, timeframe

\section{INTRODUCTION}

On boarding process, also known as organizational socialization, refers to process through which new employees acquire the necessary knowledge, skills and behavior to become effective organizational members. It includes formal meetings, lectures, reviews, materials or computer based orientation to introduce new employees to their new jobs and organizations. This techniques leads to positive outcomes for new employees such as higher job satisfaction, better job performance, greater organizational commitment and reduction in occupational stress. Thus, on boarding process plays a vital role in building the initial relationship between an employee and an organization. On boarding has four distinct levels, the Four C's:

1. Compliance is the lowest level and includes teaching employees basic legal and policyrelated rules and regulations.

2. Clarification refers to ensuring that employees understand their new jobs and all related expectations.

3. Culture is a broad category that includes providing employees with a sense of organizational norms both formal and informal.

4. Connection refers to the vital interpersonal relationships and information networks that new employees must establish.

The building blocks of successful on boarding are often called the Four C's. The degree to which each organization leverages these four building blocks determines its overall on boarding strategy. In today's scenario, the on boarding process is carried out manually by the administrator, which is time consuming and tedious. Thus, the need of the hour is to develop efficient yet inexpensive technology which will help organizations to overcome the challenges faced during this on boarding process. Thus leading to increase in the productivity of the business. Thus, our proposed system aims to replace this on boarding process by robot, which will perform all the actions taken to complete the process, hence improving timeframe. This automation not only helps reduce the cost incurred due to manual errors and inefficiency, but also enables transparency within an organization. This will be particularly important to an organization looking to retain a competitive advantage in an increasingly globalized workforce. This will also help in maintaining enthusiasm, effectiveness, retention and productivity of employees.

\section{LITERATURE SURVEY}

2.1 How Prevalent Is On Boarding?

Aberdeen Group's first report in 2006 entitled on boarding Benchmark Report identified only $40 \%$ of all organisations having a formal on boarding strategy. This number grew to $62 \%$ in Aberdeen Group's (2008) report. Their expectation was that in 2009 this figure would grow to $77 \%$.

Three drivers were identified for this increase namely; 
New employee retention - 70\%

New employee productivity - 53\%

Company reputation in recruiting top talent $-41 \%$ These drivers changed over time. Aberdeen Group's (2006) report identifies productivity as the number 1 driver in 2006, while in 2008 it changed to employee retention. Aberdeen Group's (2006) (1) report is based on a survey of over $600 \mathrm{HR}$ professionals, in a wide variety of industries (largest being aerospace at $17 \%$ ), with $55 \%$ located in North America and the balance in the UK and Asia-Pacific region. The companies are all large, $37 \%$ with annual revenue above \$1 Billion, $29 \%$ with revenue between \$50Million and \$1 Billion and $34 \%$ below $\$ 50$ Million.

\subsection{What Should Be Included In On Boarding Processes?}

Amour (2000) cites a Harvard study that identifies that $80 \%$ of employee turnover is as a result of mistakes in the hiring phase and the reason for this is mainly attributable to new employees not fitting in with the culture of the company. On the realization of this issue, companies are now more focused on ensuring that the on boarding process includes information about the company's culture. This should be followed by enough reinforcement so that the new employees can understand it and can fit in with it (Garger, 1999). Silkroad Technology Inc. is a talent management solutions company based in Winston Salem North Carolina USA. It has offices throughout the world and is regarded as a leader in the field of on boarding solutions. Silkroad (2009) point to 7 elements that need to be contained in an on boarding process for it to be successful;

1. Start before day 1

2. Socialise.

3. Extend beyond day 1 .

4. Assign a Mentor / Buddy

5. Get manager involved

6. Measure the success

7. Automate the process

Each of these 7 elements will be looked at individually.

\subsubsection{Start before Day 1}

Tradition has dictated companies to start their on boarding process when the new employee comes through the front door on their first day of employment. The employee will be very anxious wondering what their first few days will be like. If this anxiety was in some way alleviated by providing the employee the ability to have advance access to the information that they will be looking for in their first few days, the employee will feel more positive in their position. Friedman (2006) highlights that preparation is one of the key tasks in the on boarding process. It is in the period between acceptance of the position and the start of employment that this preparation should begin. The idea of including staff, that have not actually started with the company in team planning and communications meetings can seem at first to be a bit "off the wall" but with further consideration is a very good concept (Bradt \& Vonnegut, 2010). This idea may not suit all companies for reasons of confidentiality. But these issues can be and sometimes are addressed within the employee's contract of employment.

\subsubsection{Socialize}

On boarding programs help new employees socialize into the company and "get them up to speed" (Lee, 2006). One of the first recognized papers on socialization was Van Maanen and Schein (1979) in which they identified socialization as a process where an employee can acquire the traits needed to be a successful participant in a new organisation. These traits include attitude, behaviour and knowledge.

Van Maanen and Schein (1979) went further and identified 6 dimensions of socialization tactics of an organisation. The six dimensions are;

1. Collective vs individual socialization processes

2. Formal vs informal

3. Sequential vs variable

4. Fixed vs variable

5. Serial vs disjunctive

6 . Investiture vs divestiture

Saks and Gruman, (2011) argue that there is a relationship between socialization tactics and higher levels of engagement in newcomers. They state that these higher levels are because "institutionalized socialization tactics provide new hires with the information, guidance, direction and social support they need to experience meaningfulness, safety and availability". Making newcomers feel that they are part of the team or the family, whichever way the company refers to its staff, is vital to the engagement of the newcomer. Socialising newcomers is therefore an important part of the on boarding process. It is therefore incumbent on the company to providing events that make this happen.

\subsubsection{Extend Beyond Day 1}

Savitt, (2012) identifies Norton Healthcare's approach to on boarding that has 3 phases. The first stage lasts for 1 week and is purely an introductory process of the new employee to the organisation. The second phase is from the first week to 30 days and focuses on the company's clients. The third phase extends from 30 days to 90 days. This last stage helps new 
employees deal with the stresses of the job, establishing a work / life balance and creating their own personal and professional plan for their career in the company.

\subsubsection{Assign a Mentor / Buddy}

Loveland (2012) identifies that the purpose of his Buddy Program in Disney is to help Cast Members become more comfortable in their new role in a shorter period of time. It provides a one-point access to questions about the company, its culture, its procedures and policies and provides support, advice and encouragement for newcomers. A number of companies use this buddy system and Rigby (2008) identifies leading companies such as Google and Innocent and other consultancy companies like Penna that extol the virtues of buddy systems in on boarding processes.

\subsubsection{Get Manager Involved}

It is important that managers get to meet newcomers at a very early stage in the on boarding process. This can be done in conjunction with having an event to get the staff and newcomers together. Managers should attend and speak at these meetings. They can be the conveyers of the culture and ethos of the company. They can let newcomers know what is expected from them and what management and staff will do to help them acclimatize to the structures of the company (Bradt \& Vonnegut, 2010).

\subsubsection{Measure the Success}

In order to measure the success of the on boarding process feedback on the process is required. Feedback both from new employees who are going through the on boarding process and those that have just completed it, should be gathered. This feedback needs to be reviewed and looked at objectively. Items relating to parts of the on boarding process that require improvement, will be easily identifiable. Bourdeau (2011) identifies that Birchwood holds lunches for those employees that have completed their 90 day on boarding process. During the lunch feedback is requested and gathered. They have found this process to be very successful with many issues identified that were easily fixable.

\subsubsection{Automate the Process}

They utilise a software program as part of their on boarding process. It is a collaborative application that they call Chatter. It is essentially like a social media board. It helps people get connected with other team members. Each new hire is part of a Chatter Group that is cross functional. It includes team members from various groups such as IT, finance, sales operations and from locations across the globe. It provides a forum for discussion, ideas, networking and solutionising (Schneidermeyer, 2010).

\subsection{Mistakes To Avoid}

Vernon (2012) identifies 5 commonly made mistakes when it comes to effective on boarding processes employed by companies.

1. Failing to engage employees on the first day

2. Failing to articulate clear responsibilities

3. Failing to address cultural fit

4. Failing to link on boarding to desired skills

5. Failing to deliver feedback early and often

\subsubsection{Failing to Engage Employees on the First} Day

The first day should not just be used as a reading session on compliance documentation; the first day should also show how the new employee can become a valued team member.

\subsubsection{Failing to Articulate Clear Responsibilities}

Identify each of the repeatable tasks that are required of the new employee. Identify how these tasks are managed, how each task relates to the overall higher level objectives and the parameters for successful completion. Bell\& Kozlowski (2002) identifies that clear direction and goals enhance individual self-regulation and enables team members to monitor their own performance.

\subsubsection{Failing to Address Cultural Fit}

O'Reilly, Chatman, \& Caldwell, (1991) discuss the importance of understanding the fit between individuals' preferences and organizational cultures. Consistent discussion and reinforcement of the company's culture is required to be provided by the employee's management so that the employee understands the way the company works, the jargon employed and the reasoning for company events. In a 2010 interview with Forbes magazine Zappo's CEO Tony Hsieh is quoted as saying "If you get the culture right, than a lot of really amazing things happen on their own".

\subsubsection{Failing to Link on Boarding to Desired} Skills

Identify exactly what skills the new employee needs to master to be successful and then working backwards ensure that those skills are included in the on boarding process.

\subsubsection{Failing to Deliver Feedback Early and Often}

Scientists agree that it can take 90 days to form a habit, 21 days to break a habit and 40 days to change a bad habit into a positive one (Maltz, 1960). The on boarding process tries to make the workplace tasks into habitual behaviours. So it is therefore important to identify at an early stage where bad habits are developing and request employees to tweak their behaviours that do not 
support success. This process should begin from day 1 and be consistent and periodic throughout the on boarding process. If mistakes like these are made then the employee just becomes one of Garger (1999)'s 80\% statistics and leaves the company.

\section{System Architecture}

As shown in fig. below, Admin and/or HR will maintain an excel file, which will contain all the details of new hired employees. This excel file will act as an input to on boarding process. This on boarding process will now be responsible for allocating resources and creating user ids/accounts of new employees for various applications and/or software such as Airwatch, WebEx, SAP etc. It also be responsible for Email management, Mobile device management, Identity management and Mobile security.

Active Directory is a database that keeps track of all users' accounts and passwords in your organization. It allows you to store user accounts and passwords in one protected location
Oracle E business suite consists of collection Enterprise Resource Planning (ERP), Customer Relationship Management (CRM), and Supply Chain Management (SCM) computer applications either developed by or acquired by oracle. The software utilizes Oracle's core Oracle relational database management system technology. WebEx is a company that provides on demand collaboration, online meeting, web conferencing and video conferencing applications. Hence, using WebEx meetings, training centers, support centers and Sales center will be managed.

Airwatch is a provider of Enterprise Mobility Management (EMM) software and standalone management system for content, applications and email. It will enable users to selfactivate devices by entering their corporate credentials. It will also allow employees to connect to enterprise email, VPN, wi-fi, content, intranet sites and other backend resources. With airwatch it is also possible to configure policies for device restrictions, layout, settings access, notifications etc.
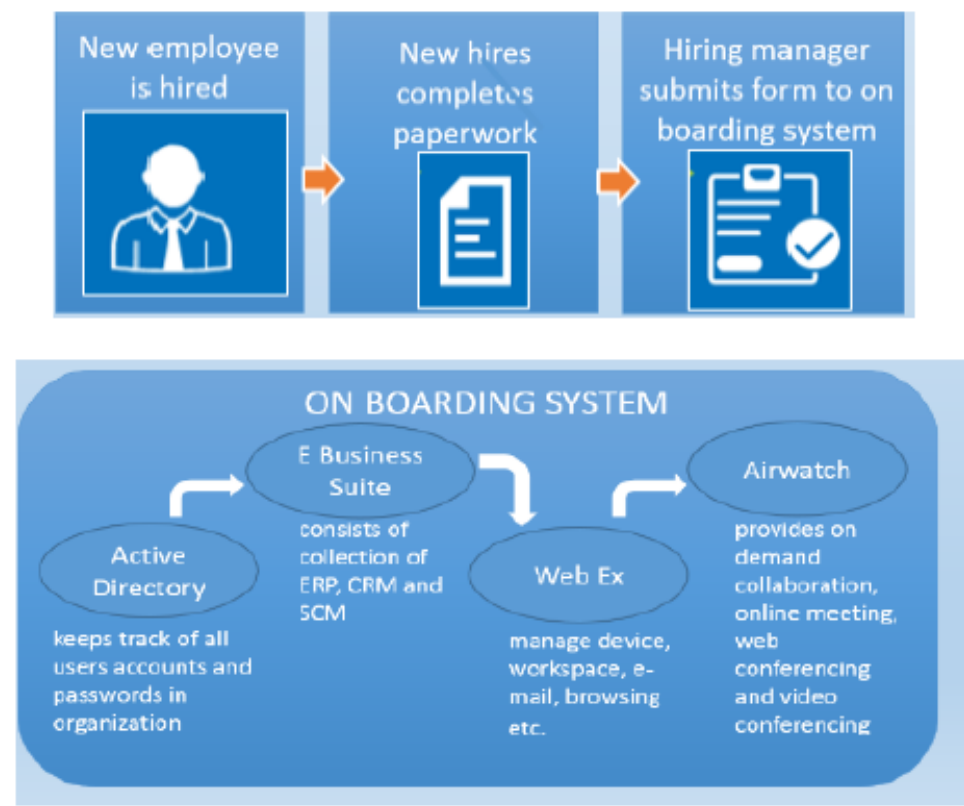

Fig. Error! No text of specified style in document. System architecture

The on boarding process through automation or by robot will:

1. Create Accounts/user id for different applications (Active Directory, WebEx, Airwatch etc.).

2. Assign roles (AD)

3. Create Email id (MS-Exchange)

4. Allocate Machine (VMware)

5. Allocate Workstation

For new hired employees which are assimilating into an organization

\section{CONCLUSION}

In today's scenario, the on boarding process is carried out manually by the administrator, which is time consuming and tedious. The proposed system aims to automate this process by robot. The main objective of process is to boost the timeframe and increase efficiency and productivity of business. It also helps to build and strengthen relationship between an organization and an employee. This automation will not only reduce the cost incurred due to manual errors and inefficiency, but also enables transparency within 
an organization. The on boarding process will create accounts or user id, assign roles, allocate workstation and machine for the new hired employees.

\section{REFERENCE LIST}

[1]. Aberdeen Group, (2006). Onboarding Benchmark Report - Technology Drivers help Improve the New Hire Experience. Aberdeen Group Report.

[2]. Aberdeen Group, (2008). All aboard; Effective Onboarding Techniques and Strategies. Aberdeen Group Report.

[3]. Aberdeen Group, (2011). Onboarding 2011 The Path to Productivity. Aberdeen Group Report.

[4]. Amour, D., (2000). Ten ways to retain highperformance employees. The Canadian Manager, 25(2), pp. 21-21,28.

[5]. Bell, B., Kozlowski,S., (2002) A typology of virtual teams implications for effective leadership. Group \& Organization Management 27.1 14-49.

[6]. Bourdeau, A., (2011). The Perfect Introduction: Getting Onboarding Right. ProfitGuide.com. published online 29th August 2011

[7]. Bradt, G., Vonnegut, M., (2010). How to get your New Employees Up to Speed in Half the Time. John Wiley \& Sons.

[8]. Buchanan, L., (2010). Welcome Aboard. Now run! ABI/Inform Global pg. 95.

[9]. Collins,(2013).Collins English Dictionary, http://www.collinsdictionary.com/dictionary /english, date accessed 15th February 2013

[10]. Collins, J., Hussey, R., (2009). Business Research: A Practical Guide for Undergraduate and Postgraduate Students, Palgrave MacMillan, Basingstoke.

[11]. Day, K., Fedele, L., (2012). Learning at the Speed of Life. T + D Magazine. 66 (6) pg. 61.

[12]. Friedman, L., (2006). Are you Losing Potential New Hires at Hello? T+D Magazine. 60 (11)

[13]. Garger, E. M. (1999). Holding on to High Performers: A Strategic Approach to Retention. Compensation and Benefits Management, 15(4), 10-17.

[14]. Ghauri P. \& Gronhaug K. (2005). Research Methods in Business Studies. 3rd ed. Pearson Education Limited. Pg15.

[15]. Hill, J., Trist, E., (1955). Temporary Withdrawal from Work Under Full Employment - The Formation of an Absence Culture. Human Relations, 8 pg. 121-152
[16]. Horn, R., (2009), Research \& Writing Dissertations: A complete Guide For Business and Management Students, London, CIPD.

[17]. Jankowicz, A., (2004), Business Research Projects. 4th Edition Abebooks Ltd.

[18]. Kjerulf, A., (2007), Happy Hour is 9 to 5 How to Love Your Job, Love Your Life and Kick Butt at Work. 1st Edition. Alexander

[19]. Lee, D. (2006). Successful Onboarding: How to Get Your New Employees Started Off Right. Available Online at www.humannatureatwork.com/articles/onbo arding/successful_onboarding.htm

[20]. Likert, R., (1932). A Technique for the Measurement of Attitudes. Archives of Psychology. 140: 1-55.

[21]. Loveland, G., (2012). Disney English's Onboarding Buddy program. Training Magazine. On line published 30th July 2012 -23.00 .

[22]. Maltz, M., (1960). Psycho-Cybernetics: A New Way to Get More Living out of Life. Prentice-Hall. 